\title{
Primary Angioplasty of a Super Dominant Left Anterior Descending Coronary Artery
}

\author{
Laxman Dubey ${ }^{1}$, Ridhi Adhikari ${ }^{2}$, Pradip Jung KC ${ }^{3}$, Rajesh Panjiyar ${ }^{3}$, Tej Bahadur Gurung ${ }^{3}$, Gan- \\ gapatnam Subramanyam ${ }^{4}$

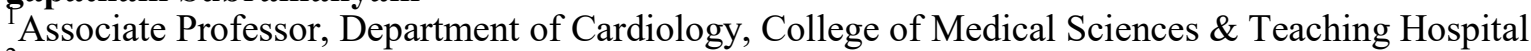 \\ ${ }^{2}$ Lecturer, Department of Radiodiagnosis, College of Medical Sciences \& Teaching Hospital \\ ${ }^{3}$ Lecturer, Department of Cardiology, College of Medical Sciences \& Teaching Hospital \\ ${ }^{4}$ Professor, Department of Cardiology, College of Medical Sciences \& Teaching Hospital
}

\section{Correspondence \\ Dr. Laxman Dubey, \\ Department of Cardiology, \\ College of Medical Sciences \& \\ Teaching Hospital \\ Bharatpur, Nepal \\ Email: dubeylax@yahoo.com}

DOI: http://dx.doi.org/10.3126/ jcmsn.v12i2.15457

Article received: May 8th 2016

Article accepted: July $1^{\text {st }} 2016$

\begin{abstract}
The posterior descending artery usually arises from either the right coronary artery or the left circumflex artery. Here we report an unusual case of super-dominant left anterior descending coronary artery continuing as the posterior descending artery beyond the crux which was totally occluded in a patient who presented with acute anterior wall myocardial infarction. Successful primary angioplasty and stenting of the superdominant left anterior descending coronary artery was performed.

Key words: Angioplasty; Coronary artery; Left anterior descending; Super dominant
\end{abstract}

Citation: Dubey L, Adhikari R, KC PJ, Panjiyar R, Gurung TB, Subramanyam G. Primary Angioplasty of a Super Dominant Left Anterior Descending Coronary Artery. JCMS Nepal. 2016;12(2):81-82.

\section{INTRODUCTION}

In $85 \%$ of patients there is right dominant circulation which refers to a pattern in which the right coronary artery (RCA) gives rise to the posterior descending artery (PDA), posterolateral branches and the atrioventricular nodal artery. However in $8 \%$ cases there is left dominant circulation which refers to when the left circumflex artery (LCx) gives origin to these vessels. The term 'co-dominance' ( $7 \%$ of patients) refers to when the PDA arises from the RCA and the posterolateral branches from the LCx. ${ }^{1}$ It is rare for the PDA to originate from the left anterior descending coronary artery (LAD) even though continuation of the LAD around the apex is common. When the LAD goes beyond the crux and gives rise to PDA, it is termed as super-dominant LAD. Here we report a very rare case of primary angioplasty and stenting of a totally occluded super-dominant LAD in a patient who presented with acute anterior wall myocardial infarction (MI).

\section{CASE REPORT}

A 51-year-old man was admitted to our hospital with acute onset central chest pain associated with profuse sweating for 12 hours and shortness of breath of three hours duration. At admission, patient was severely dyspnic. His pulse rate was 110 beats per minute and regular, while blood pressure was $70 / 50 \mathrm{~mm} \mathrm{Hg}$. On auscultation, an S4 was present. Rales were present nearly all over the lungs. Electrocardiography showed sinus tachycardia and ST segment elevations in leads V1-V4, suggestive of acute anteroseptal wall MI. Written informed consent was obtained for primary percutaneous intervention and the patient was shifted immediately to the catheterization laboratory. Coronary angiography revealed that the left main coronary artery was normal and gave off the large left anterior descending (LAD) and left circumflex (LCx) arteries. The LCx was a non-dominant artery and free of disease. The LAD continued in the anterior interventricular groove with 100\% occlusion after the first septal branch (Figure 1). The right coronary artery was a non-dominant vessel arising from the right coronary sinus, and was free of disease (Figure 2). The patient underwent successful primary angioplasty and stenting to the mid LAD. Post procedure selective coronary angiogram of left coronary artery showed thrombolysis in myocardial infarction III (TIMI-III) flow in the LAD which continued as the posterior descending artery (PDA) (Figure 3). 


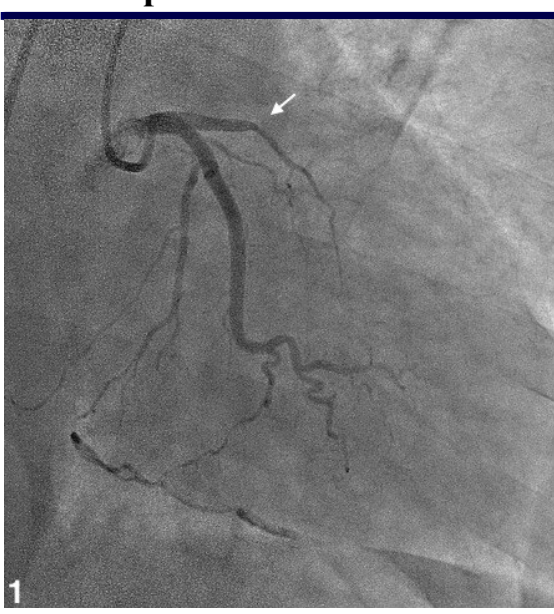

Fig 1: Coronary angiogram in the right anterior oblique (RAO) caudal projection showing total occlusion at mid part of the left anterior descending artery (white arrow)

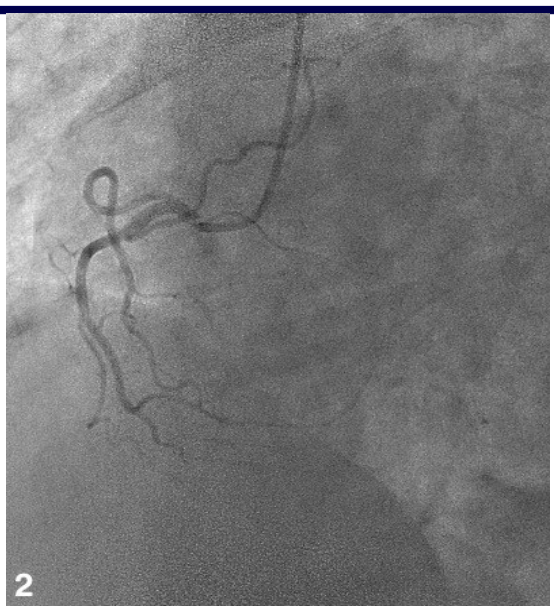

Fig 2: Coronary angiogram in the left anterior oblique (LAO) cranial projection showing non-dominant right coronary artery

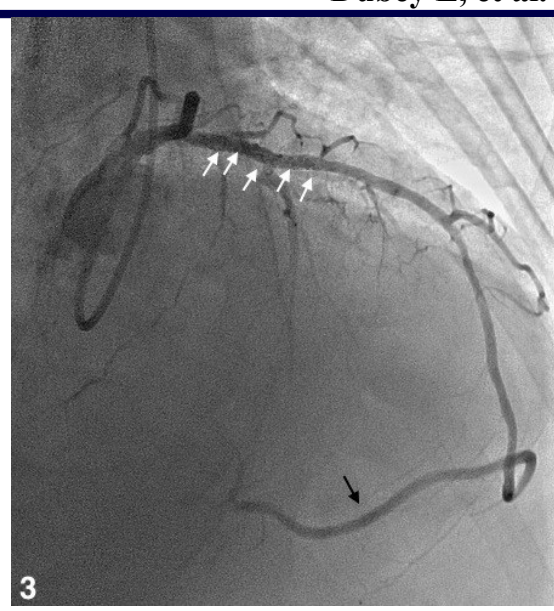

Figure 3: Coronary angiogram in the right anterior oblique (RAO) cranial projection showing left anterior descending artery continuing as posterior descending artery (black arrow) after primary angioplasty and stenting (white arrows)

\section{DISCUSSION}

Congenital anomalies of the coronary arteries are present in about $1.3 \%$ of adults undergoing cardiac catheterization. ${ }^{2}$ It could be considered an incidental finding without clinical significance. ${ }^{3}$ However, depending upon the origin, course, and termination of the anomalous vessel, these abnormalities may be responsible for angina pectoris, heart failure and sudden death. ${ }^{4}$ Normally posteroinferior part of the interventricular septum is supplied by the PDA whose variable origin is reflected by the concept of coronary dominance. ${ }^{5}$ In right dominant circulation, the PDA arises from the RCA ( $85 \%$ of patients) and co-dominance $(7 \%$ of patients) or from the $\mathrm{LCx}$ in a pattern of left dominance $\left(8 \%\right.$ of patients). ${ }^{1}$ An extremely rare form of left dominant coronary circulation reported in the literature is the continuation of the LAD beyond the crux into the posterior interventricular sulcus as the PDA supplying most of the interventricular septum. ${ }^{5}$ However, there are only a few case reports where the LAD continued as a PDA beyond the crux. ${ }^{1}$ Acute MI with total occlusion of such super-dominant LAD results in massive infarction of the anterior wall, septum and inferior wall, leading to cardiogenic shock, similar to our patient. Therefore, early revascularization is probably lifesaving for these patients.

\section{CONCLUSION}

LAD that continues as a PDA is a very rare finding, which, if totally occluded, may lead to massive infarction and fatal consequences. Therefore, early revascularization is probably lifesaving for these patients.

\section{CONFLICT OF INTEREST: None}

\section{REFERENCES}

1. Mannuva BB, Durgaprasad R, Velam V. Hyperdominant left anterior descending artery continuing as posterior descending artery: a rare coronary artery anomaly. CathLab Digest 2013;21(1)

2. Yamanaka O, Hobbs RE. Coronary artery anomalies in 126,595 patients undergoing coronary arteriography. Cathet Cardiovasc Diagn 1990;21:28-40

3. Dubey L. Percutaneous coronary intervention of an obstructive left anterior descending artery with anomalous origin of right coronary artery. ARYA Atheroscler 2013;9:164-6

4. Dubey L. Anomalous origin of the coronary arteries: an account of six cases. J Nepal Med Assoc 2013;52:512-6

5. Ramesh Babu CS, Khare S, Asthana AK, Saxena S, Gupta OP. Posterior descending artery arising as a continuation of hyperdominant left anterior descending artery. Int J Anat Radiol Surg 2015;4:16-19 